\title{
Community interviewing: experiences and recommendations
}

\author{
Sue Parkman and Sara Bixby
}

\begin{abstract}
Evaluation studies of community mental health services require the resecarch, ofien in the form of interviews, to be carried out in private homes which poses a particulor set of baves relating to the interview environment and the organiscation of the work. This paper describes the experiences of interviowing patients, staff and informal corers as pat of an evaluation study of the mental heatth services in two peychiatilic sectors in South London and makes recommendations for more eftective community based research.
\end{abstract}

With the long-term trend towards "community care', increasing numbers of people with mental illness are being cared for by the health and social services in their own homes. PRiSM (Psychiatric Research in Service Measurement) is based at the Institute of Psychiatry, and funded by the Department of Health, to evaluate community mental health services for people with severe mental illness in two inner city districts of South London. Interviews with patients, their relatives and with formal carers are carried out, often in people's homes, to collect data on a wide range of outcome measures, including use and satisfaction with the mental health services, current state of physical and mental health, assessment of needs, quality of life, and educational, work and family background. Several issues have arisen in our work which have prompted us to assess our own roles and skdlls as interviewers working in community settings. This paper discusses these issues and makes recommendations for more effective community based research.

\section{The interview setting}

Interviewing someone in their own home can be both beneficial and detrimental to the quality of the interview. It is of benefit to people who are physically frail or disabled, and for many people it is more relaxing and helps put them at ease. At home, the respondent usually feels more confident with the interviewer and therefore more able to relate experiences and opinions openly and honestly. However, some people consider it to be an invasion of their privacy and prefer to meet in our offices. Other members of the household or neighbours might not be aware of their mental health problems and the presence of the researcher could be awkward and embarrassing to explain. Therefore, respondents should be given a choice of location for the interview and researchers should be aware of the sensitive nature of their work when making contact with the respondent. For example, messages should not be left on an answerphone unless permission has been sought from the respondent.

While it is made clear to clients beforehand that for reasons of confidentiality the interview should be carried out on a one to one basis, in practice this can be difficult to ensure in someone's home. If the respondent is living with others, interruptions may occur which can cause a loss of concentration and interrupt the flow of the interview. The television or radio may be on and the telephone may ring. It may be difficult to interview the respondent alone because of a lack of space or because another member of the household wants to be involved in the interview; the respondent may also prefer this.

From the perspective of the researcher, interviewing someone in their own home enables the researcher to develop a fuller understanding of the person's social and family situation and, providing the environment is safe, is usually a better option.

\section{Confidentiality}

The interviewer may come upon a situation where respondents are potentially at risk to themselves

\section{Table 1. Key points in conducting the interview}

- Glve respondent choice in location of interview

- Be sensittive to wishes of respondent for confidentiality

- Look out for indicators of tiredness or distress during the interview

- Always end the interview on a good note 
or to others. This raises the issue of confidentiality and before seeking outside help the interviewer needs to ascertain with the respondent whether they wish to seek help themselves or prefer the interviewer to intervene on their behalf. It can be difficult to judge the degree of risk at one visit and only in extreme circumstances, for example possible child abuse, or suicide, does intervention occur. PRISM has a code of practice which includes the premise that before taking action the situation should first be discussed with a senior member in the team and that guarantee of confidentiality may be overidden by a need to intervene only in extreme situations. So far, after interviewing 207 people, this has occurred on three occasions.

\section{Interviewer safety}

As well as benefits, there are risks attached to interviewing people at home. Expensive equipment such as a laptop computer should be carried unobtrusively. If respondents are to recetve payment for participating it is advisable that the money be sent in the form of a postal order rather than being given as cash, to minimise the risks to the interviewer; this should be explained before the start of the interview. A system has been set up within the team whereby researchers inform a named member where they are going and their expected time of return. There are written guidelines for what to do if the researcher falls to return at the expected time and the local police station is aware of our arrangements. Mobile telephones with pre-programmed emergency telephone numbers are avallable for interviewers.

Although the majority of people who suffer from severe mental illness do not pose a threat, there is a minority who have a history of violence and aggression. Although threatening behaviour has only been shown on two occasions to us, it is necessary to take precautions, particularly when visiting people who have little or no contact with the services. Training in the prevention and management of violence is offered to clinical workers and should also be offered to interviewers. In the PRISM study, contact is established with the appropriate formal carer before

Table 2. Key points in safety

\footnotetext{
- Inform someone where you are going and when you expect to return

- Do not carry valuables

- Send any payment for the interview separately

- Carry equipment, e.g. laptop, discreetty

- Have a system in place for what to do in the event that a researcher does not return
}

approaching the patient so that any risk can be assessed. When this is not possible, two interviewers go together when visiting the respondent for the first time to gauge the situation.

\section{Efiects of the interview on the respondent}

In a study investigating the effects of mental health surveys on respondents, there was no reported incidence of extreme distress and only a small minority of those surveyed reported a negative effect (4\% distressed; $1 \%$ depressed). The majority (52\%) reported that the survey made them feel good about themselves (Jorm et al, 1994). Distress may be indicated by a change in the respondent's manner - in their eye contact. intonation of their voice and they may become more tense or restless. If distress is being caused by particular questions, it may not be appropriate to continue and so the interview needs to be concluded sensitively so that the respondent is not left in a state of distress. Patients with chronic psychotic illnesses may find it difficult to concentrate for any length of time and so the interviewer needs to retain a sensitivity to the ability and willingness of the patient to continue with the interview; it may be necessary to carry out the interview on several occasions. The training needs of researchers working with a particular client group should be considered by the research team (Jorm et al, 1994).

\section{Efiects of the interview on the interviewer}

As researchers, interviewing someone at their home allows a greater understanding of the situation. However, the corollary to this is the sense of powerlessness which is often felt due to the inability to intervene; this is compounded by the physically isolated nature of the work. On a daily basis, many hours are spent visiting people in their homes, with a substantial amount of cancelled appointments and wasted time in travelling to the appointments. Being able to feed back informally between ourselves and having weekly team meetings are invaluable sources of support. We have also found that organising the interviews into discrete batches and having a weekly team meeting helps to foster a sense of progress and achievement.

\section{Organisational aspects}

Where possible. identification of a formal (key) carer for a client is the first stage in the research process (Dayson, 1990); this allows an assessment of the client's needs and functioning in the previous month. It also enables the carer to be 
involved and to advise on whether it is appropriate to contact the respondent and if so, the most suitable way to do so (letter, telephone or via the formal carer). In cases where clients are approached by letter a mixed approach of sending one letter stating a fixed appointment time and another suggesting that a researcher will be visiting within the next week seems to be the most efficient way of making contact. If the formal carer wishes to ask the client if she/he is willing to participate, then the carer may set up the first meeting for the researcher. Where the formal carer has wanted to remain involved this has helped in maintaining contact and cooperation between the clinical and research teams.

\section{Comment}

Interviewing in the community is physically isolating and requires an abllity to deal with a variety of unfamiliar situations appropriately and effectively. At times, the inability to directly intervene can lead to a sense of powerlessness. People with severe mental illnesses often have difficulties with concentration, disorganisation and psychotic symptoms. The experience from the PRISM team has demonstrated the need for appropriately skdlled staff who have access to adequate resources for training and a good network of formal and informal support at the team base.

\section{References}

DaYson, D. (1990) The TAPS Project 2. Challenges and pitfalls of community interviewing. Psychiatric Bulletin. 14, 651-653.

JoRM, A. F.. HEnderson, A. S., Scott, R., et al (1994) Do mental health surveys disturb? Further evidence. Psychological Medicine, 24, 233-237.

*Sue Parkman, Researcher, and Sara Bixby Researcher; PRISM (Psychiatric Research in Service Measurement), Institute of Psychiatry. De Crespigny Park, London SE5 8AZ

*Correspondence

\section{Psychiatric Aspects of Physical Disease}

\section{Edited by Allan House, Richard Mayou \& Christopher Mallinson}

This book describes the extent and nature of psychiatric problems associated with physical illness and the ways in which both can be managed by physicians and psychiatrists. Examples are given of simple measures that can be incorporated into routine care and of occasions where specialist referral is appropriate. The book comprises edited papers based on a joint conference of the Royal Colleges of Physicians and Psychiatrists together with additional editorial sections. It provides a sister volume to Medical Symptoms not Explained by Organic Disease and complements the joint report of the two Colleges on Psychological Care of Medical Patients: Recognition of Need and Service Provision.

\section{$\bullet £ 15.00 \bullet 110$ pp. $\bullet 1995 \bullet$ ISBN 1873240929}

Available from bookshops and from the Publications Department, Royal College of Psychiatrists, 17 Belgrave Square,

London SW1X 8PG (Tel. 0171-235 2351, extension 146) 